\title{
Comparison of Elbow Extensor Muscle Strength and EMG Activity in Supine and Prone Positions in Healthy Subjects
}

\author{
Ui-jae Hwang, PT, Ph.D. ${ }^{1}$; Jun-hee Kim, PT, Ph.D. candidate ${ }^{2}$; \\ Gyeong-tae Gwak, PT, BHSc ${ }^{2}$; Moon-hwan Kim, PT, Ph.D. ${ }^{3}$ \\ ${ }^{1}$ Department of Rehabilitation Therapy, Graduate School, Yonsei University, Wonju, Korea \\ ${ }^{2}$ Department of Physical Therapy, The Graduate School, Yonsei University, Wonju, Korea \\ ${ }^{3}$ Department of Rehabilitation Medicine, Wonju Severance Christian Hospita, Wonju, Korea
}

Background There is little research on the strength and electromyograph (EMG) activity of elbow extensors according to the measuring posture.

Purpose We investigated which posture influenced strength and EMG activity of elbow extensors in evaluating postures (supine and prone).

Study design Comparative, repeated measures design.

Methods Twenty-one healthy subjects performed maximal elbow extension in two postures (supine and prone). EMG activity was measured in the anconeus, long head of triceps (LoT), and lateral of triceps (LT). When measuring EMG activity of elbow extensors, the strength of elbow extensors was also measured by Smart KEMA strength measurement system.

Results In supine, EMG activity of anconeus and LT was significant increased. The other way, EMG activity of LoT and strength of elbow extensors were significant increase in the prone position.

Conclusions We recommend the prone position to increase EMG activity of LoT and to improve strength of elbow extensors. In addition, supine position should be considered to increase muscle activity of anconeus and LT.

Key words Axial-thoracolumbar rotation; Measurement; Reliability; Trunk rotation.

Journal of KEMA 2018; 2(1): 16-19 Published Online June 30, 2018 pISSN: 2586-4351 eISSN: 2586-5706

Article History Received 06 April 2018 Revised 24 April 2018 Accepted 10 May 2018

\section{CONTACT}

agafimu@hanmail.net Moon-hwan Kim, Department of Rehabilitation Medicine, Wonju Severance Christian Hospita, Wonju, Korea

\section{This is an Open-Access article distributed under the terms of the Creative Commons Att- ribution Non-Conmercial Li- cense (hittp.//creativecommons. org/licenses/by-nc/4.0) which permits unrestricted non-co- mmercial use, distribution, and reproduction in any medium provided the original work is} properly cited.

\section{INTRODUCTION}

The anconeus and triceps brachii are primary extensors of the elbow. ${ }^{1}$ The anconeus extends from the olecranon to the dorsolateral part of the lateral epicondyle. ${ }^{2}$ The main action of the anconeus is accessory extension of the elbow. ${ }^{3}$ This muscle also acts as a stabilizer for the elbow joint during supination and pronation. ${ }^{4}$ The triceps brachii is a threeheaded muscle (long, lateral, and medial). ${ }^{5}$ The long head (LoT) is attached to the olecranon from the infraglenoid tubercle of the scapula. ${ }^{1}$ Therefore, the LoT serves to extend and adduct the shoulder and extend the elbow. ${ }^{6,7}$ The medial and lateral heads (LT) originate from the posterolateral aspect of the humerus, and their main function is elbow extension with the LoT. ${ }^{1,7}$

In clinical, the elbow extensors are strengthened to increase the ability of spinal cord injury patients in a push wheelchair to transfer from one place to another and to reach objects during activities of daily living. ${ }^{8}$ Athletic trainers' use several exercises to strengthen the elbow flexors and extensors for elbow balance. Strengthening the triceps is especially important in cross-country sports to improve high propulsion force. ${ }^{9}$

However, activities that increase muscle strength during elbow extension by shoulder posture remain to be investigated. Two positions are generally adopted to measure the 
strength of the elbow extensors: supine and prone. ${ }^{5}$ Therefore, the purpose of this study was to compare the electromyography (EMG) activity of the anconeus, LT, and LoT and the force of the elbow extensors during elbow extension in the supine and prone positions.

\section{METHODS}

\section{Subjects}

This study included 21 healthy subjects (19 male, 2 female; mean age: $23.33 \pm 1.83$ years; height: $174.5 \pm 6.90 \mathrm{~cm}$; weight: $75.38 \pm 13.01 \mathrm{~kg}$ ). Exclusion criteria were neuromuscular disorder of the shoulders and upper extremities, limited motion of shoulder and elbow joints, and fracture of the upper extremity (especially the elbow joint). All subjects participated voluntarily. Before the study, the investigator explained the experimental procedures to the subjects.

\section{Instrumentation}

A surface EMG system (TeleMyo DTS, Noraxon, Scottsdale, AZ, USA) was used to measure the activity of the anconeus, LT, and LoT. The sampling rate was 1,024 Hz. Filtered movement artifacts were eliminated using a digital band-pass filter (Lancosh FIR) at a frequency range of 20$450 \mathrm{~Hz}$. Root mean square values were used to process EMG signals with a moving window of $50 \mathrm{~ms}$. EMG signals were recorded for $5 \mathrm{~s}$, and seconds 2-4 were used for data analysis. Two electrodes were placed over the middle of each muscle belly, parallel to the muscle fibers. The electrode sites were shaved, and rubbing alcohol was used to reduce skin impedance. Electrodes were placed on the anconeus (parallel to and below the olecranon on the radial side), LT (lateral, approximately $50 \%$ of the distance between the acromion and olecranon or elbow joint), and LoT (medial, approximately $50 \%$ of the distance between the acromion and olecranon). ${ }^{10}$ EMG data were measured in the supine and prone positions. Maximum voluntary isometric contraction (MVIC) was held for $5 \mathrm{~s}$ in each position. This procedure was repeated three times in each position, with a 1 -minute rest period between sessions. The force of the elbow extensors was simultaneously measured using a Smart KEMA strength measurement system (Factorial Inc., Seoul, Korea); force was measured from the isometric strength of the elbow extensors and transferred to a tablet (Galaxy Tab A6 10.1, Samsung, Inc., Seoul, Korea) via a Bluetooth connection and analyzed using the Smart KEMA application software (Factorial, Inc.).

\section{Procedures}

All subjects were measured in the supine and prone positions randomly. Subjects wore a Smart KEMA force measurement belt on the distal part of the forearm to measure elbow extensor strength. In the supine position, measurements were conducted at maximal isometric elbow extension in $90^{\circ}$ shoulder flexion, $90^{\circ}$ elbow flexion, and forearm supination (Figure 1A). In the prone position, measurements were conducted at maximal isometric elbow extension in $90^{\circ}$ shoulder abduction, $90^{\circ}$ elbow flexion, and forearm supination. To limit shoulder movement, we placed a target bar at the elbow joint (Figure 1B).

\section{Data analysis and statistics}

The data are expressed as mean \pm standard deviation. A paired $t$-test was used to assess the significance of differ-

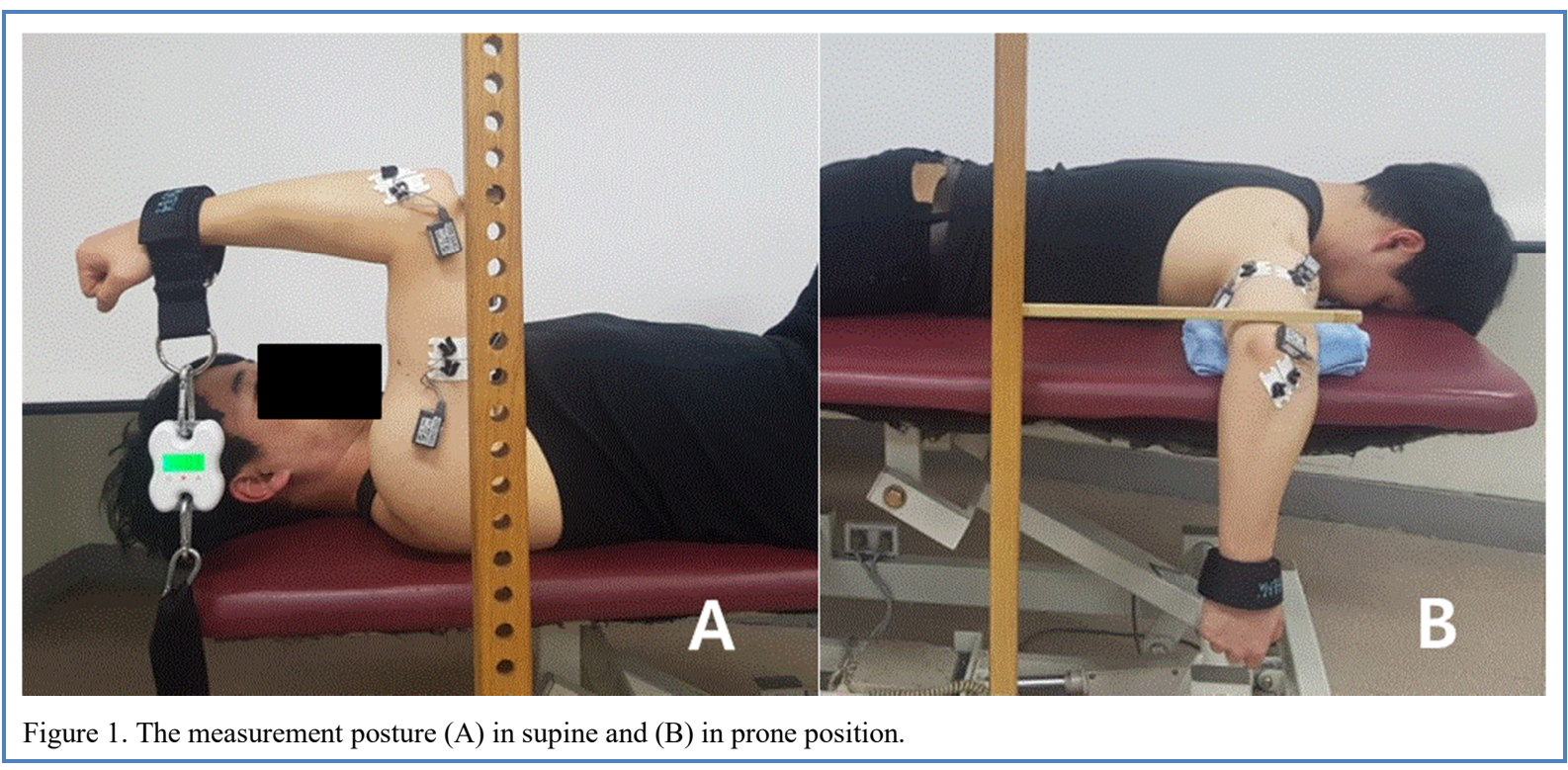


ences in EMG activity and muscle force in each position. Statistical analyses were performed using the SPSS version 21.0 software for Windows (SPSS, Inc., Chicago, IL, USA). Significance was assessed at a level of $p<0.05$.

\section{RESULTS}

The EMG activity of the anconeus and LT was significantly greater in the supine than in the prone position $(p<0.05)$ (Table 1). The EMG activity of LoT in the prone position exhibited greater than in the supine. The force of elbow extensor was significant increase in the prone position $(p<0.05)$ (Table 2).

\section{DISCUSSION}

We compared the EMG activity of the anconeus, LT, and LoT and the strength of the elbow extensors in two postures. The anconeus and LT exhibited greater muscle activity in the supine position, whereas the EMG activity of the LoT was greater in the prone position.

The anconeus acts as a stabilizer for the humeroulnar joint. ${ }^{11,12}$ The muscle fibers of the anconeus combine with those of the LT, some of which are arranged in the same direction. ${ }^{12}$ Continuity has also been detected between the fascia of the anconeus and that of the LT. ${ }^{13}$ The EMG patterns observed in this study are consistent with these previous reports.

A previous study found that the LoT, which is connected at two joints, was more effective in the supine position. ${ }^{1}$ Because the LoT is shortened at both the shoulder and elbow joints during horizontal abduction in the prone position, whereas during shoulder flexion in the supine position, it is shortened at the shoulder and lengthened at the elbow joint.

Table 1. Comparison of EMG activity of elbow extensor muscle for each position

$(\mathrm{N}=21)$

\begin{tabular}{ccccc}
\hline & In supine & In prone & $t$ & $p$-value \\
\hline Anconeus & $74.07 \pm 20.26$ & $57.40 \pm 23.00$ & -3.224 & $0.004^{*}$ \\
LoT & $77.72 \pm 19.29$ & $92.97 \pm 30.45$ & -2.143 & $0.005^{*}$ \\
LT & $77.37 \pm 19.91$ & $58.76 \pm 27.41$ & -3.780 & $0.001^{*}$ \\
\hline
\end{tabular}

LoT: long head of triceps, LT : lateral triceps.

Table 2. Comparison of force of elbow extensors for each position

$(\mathrm{N}=21)$

\begin{tabular}{ccccc}
\hline & In supine $(\mathrm{kg})$ & In prone $(\mathrm{kg})$ & $t$ & $p$-value \\
\hline \multirow{2}{*}{ Mean \pm SD } & $12.65 \pm 2.71$ & $15.94 \pm 3.90$ & 5.502 & $0.001^{*}$ \\
\hline
\end{tabular}

SD: standard deviation.
However, unlike the slight extension of the elbow observed in the previous study, elbow flexion was $90^{\circ}$ in this study. This difference in the position of the elbow joint may explain the differential results between this and the previous study. ${ }^{5}$

When we measured the force and EMG activity of the elbow extensors, the EMG activity of the anconeus and LT were significantly greater in the supine than in the prone position, whereas the muscle strength was greater in the prone position. In a comparison of triceps muscle fibers, Neumann (2002) reported that the LoT had a larger volume and physiological cross-sectional area at the elbow than did the brachialis ${ }^{1}$. The greater muscle strength of the LoT in the present study may have resulted from the measurement posture and the cross-sectional area of the LoT noted in that study.

It is important that the strength of the elbow extensors and EMG activity of LoT in the prone position was higher than that in the supine position. We recommend the supine position rather than prone to increase the muscle activity of the LT or the anconeus, which serves as an elbow stabilizer.

This study has several limitations. First, the elbow extensors were measured only in the supine and prone positions, although many strategies for strengthening them use other postures. The most common method to determine elbow extensor strength is to measure it in these two postures. Further study is needed to examine muscle strength and EMG activity in other postures. We also compared EMG values when the maximum force was applied. Future research should also measure the activity of each muscle at varying degrees of force.

\section{CONCLUSION}

Our study identified the strength and EMG activity of the elbow extensors in two positions. To increase the muscle strength and EMG activity of the LoT, elbow extension should be performed in the prone position; we also recommend that the EMG activity of the anconeus or LT be increased in the supine position.

\section{Key Points}

Question Which posture influences strength and muscle activity of the elbow extensor?

Findings We observed the largest increase long head of triceps muscle (LoT) activity and strength of elbow extensors in prone position and the more activity of anconeus and lateral triceps (LT) in supine position. 
Meaning The prone position is effective to increasing strength of elbow extensor and EMG activity of LoT. In order to higher activity of anconeus and LT, we recommended to accomplish in the supine position.

\section{Article information}

Conflict of Interest Disclosures: None.

Funding/Support: None.

Acknowledgment: None.

\section{REFERENCES}

1. Neumann DA. Kinesiology of the musculoskeletal sys-tem: Foundation for rehabilitation. 3rd ed. Elsevier; 2017.

2. Stroyan M, Wilk KE. The functional anatomy of the elbow complex. J Orthop Sports Phys Ther. 1993;17(6): 279-288.

3. Basmajian JV, Griffin WR. Function of anconeus muscle. An electromyographic study. J Bone Joint Surg Am. 1972; 54(8):1712-1714.

4. Pauly JE, Rushing JL, Scheving LE. An electromyographic study of some muscles crossing the elbow joint. Anat Rec. 1967;159(1):47-53.

5. Kendall FP, McCreary EK, Provance PG, et al. Muscles:
Testing and function with posture and pain. $5^{\text {th }}$ ed. Lippincott Williams \& Wilkins; 2005.

6. Levangie PK, Norkin CC. Joint structure and function: a comprehensive analysis. $4^{\text {th }} \mathrm{ed}$. FA Davis; 2005.

7. Sahrmann SA. Movement system impairment syndromes of the extremities, cervical and thoracic spines. Elsevier; 2011.

8. Ribot-Ciscar E, Butler JE, Thomas CK. Facilitation of triceps brachii muscle contraction by tendon vibration after chronic cervical spinal cord injury. J Appl Physiol. 2003;94(6):2358-2367.

9. Smith GA, Fewster JB, Braudt SM. Double poling kinematics and performance in cross-country-skiing. $J$ Appl Biomech. 1996;12(1):88-103.

10. Cram JR, Kasman GS, Holtz J. Introduction to surface electromyography. $2^{\text {nd }}$ ed. Eleanor Criswell; 2011.

11. O'Driscoll SW, Jupiter JB, King GJ, et al. The unstable elbow. Instr Course Lect. 2001;50:89-102.

12. Molinier F, Laffosse JM, Bouali O, et al. The anconeus, an active lateral ligament of the elbow: new anatomical arguments. Surg Radiol Anat. 2011;33(7):617-621.

13. Keener JD, Chafik D, Kim HM, et al. Insertional anatomy of the triceps brachii tendon. J Shoulder Elbow Surg. 2010;19(3):399-405. 